\title{
FORMAÇÃO CONTINUADA DE PROFESSORES EM MODELAGEM MATEMÁTICA: UM RELATO DE EXPERIÊNCIA
}

\author{
CONTINUED TRAINING OF TEACHERS IN MATHEMATICAL MODELING: AN EXPERIENCE REPORT
}

FORMACIÓN CONTINUA DE PROFESORES EN EL MODELIZACIÓN MATEMÁTICA: UN RELATO DE EXPERIENCIA

\author{
CARARO, Elhane De Fatima Fritsch 1 \\ KLÜBER, Tiago Emanuel ${ }^{2}$
}

\section{RESUMO}

O texto relata aspectos relacionados à implementação de uma proposta de formação continuada para professores de Matemática em Modelagem Matemática que se desenvolve no município de Francisco Beltrão, Paraná. A Formação busca se efetivar em caráter permanente e se desenvolve entre professores de Matemática de escola pública. A proposta inicialmente desencadeou a reflexão sobre concepções de ensino, aprendizagem da Matemática, currículo e práticas pedagógicas. Ocorreram elaborações e compartilhamentos de atividades de Modelagem Matemática pelos participantes e emergiu uma forma de apoio em rede que ensejou avanços para a efetivação e possível adoção da Modelagem Matemática nas salas de aulas.

Palavras-chave: Modelo de Formação. Tendências da Educação Matemática. Práticas Pedagógicas

\section{ABSTRACT}

The text reports aspects related to the implementation of a proposal of continuing education for teachers of Mathematics in Mathematical Modeling that is developed in the city of Francisco Beltrão, Paraná. The Training looks for to be effective on a permanent basis and develops among the teachers of Mathematics of a public school. learning of Mathematics, curriculum and pedagogical practices. There have been elaborations and shares of Mathematical Modeling activities by the participants that have triggered a form of network support, providing advances for the effectiveness and possible adoption of Mathematical Modeling in classrooms.

Keywords: Training Model. Trends in Mathematical Education. Pedagogical Practices

\section{RESUMEN}

El texto describe los aspectos relacionados con la implementación de una propuesta de educación para profesores de Matemáticas en Modelización Matemática que se desarrolla en la ciudad de Francisco Beltrão, Paraná. La formación pretende efectuar permanente y se desarrolla entre los profesores de matemáticas de una escuela pública. La propuesta provocó inicialmente la reflexión, sobre creencias respecto a la enseñanza, el aprendizaje de las matemáticas, programas de estudios y las prácticas pedagógicas. Ocurrió elaboraciones y el intercambio de las actividades de Modelización Matemática de los participantes que llevó un soporte de red de modo que ocasiona avanza para la efectividad y posible adopción aprobación del Modelización Matemática en las aulas.

Palabras clave: Modelo de Formación. Tendencias en la Educación Matemática. Prácticas Pedagógicas

\footnotetext{
1 Universidade Estadual do Centro-Oeste - UNICENTRO/Secretaria de Estado da Educação - SEED - Guarapuava - Paraná Brasil

2 Universidade Estadual do Oeste do Paraná - Cascavel - Paraná - Brasil
} 


\section{SOBRE A FORMAÇÃO DE PROFESSORES EM MODELAGEM MATEMÁTICA}

A Modelagem Matemática na Educação Matemática, segundo Burak (2004), surgiu em cursos de especialização para professores, ministrados pelo professor Rodney Carlos Bassanezi em 1983, na antiga FAFIG ${ }^{3}$, hoje UNICENTRO ${ }^{4}$. Posteriormente foi disseminada em todo o Brasil por meio de outros professores (BIEMBENGUT; HEIN, 2005).

A partir do início dos trabalhos que relacionavam a Modelagem Matemática ao ensino, em 1987, evidenciaram-se diferentes concepções de Modelagem Matemática, como aquelas concepções ressaltadas por Klüber e Burak (2008), que refletem as experiências vividas e as percepções de seus seguidores (BURAK, 2004).

Para além das diferenças entre as concepções de Modelagem é possível admitir, em todas elas, potencial para superar modelos obsoletos de ensino e de aprendizagem, favorecendo a investigação, a problematização, o desenvolvimento da autonomia e a aprendizagem de conceitos matemáticos e outros. Em certo sentido, esse potencial é utilizado como discurso de convencimento aos professores, ou seja, a mudança de atitude dos estudantes, em relação à Matemática, é assumida como um dos principais aspectos para a mudança de prática do professor. No entanto, ainda que esse seja um argumento importante, ele não é suficiente para que o professor inicie a implementação da Modelagem Matemática na sala de aula.

Nessa perspectiva, Klüber (2010) considera que o como fazer Modelagem Matemática ainda é uma das lacunas a ser superada para a implementação da Modelagem Matemática em sala de aula, pois envolve a (re)elaboração de práticas pelo professor. Demais fatores, como: a insegurança em propor aos alunos diferentes temas para desenvolver as atividades de Modelagem Matemática (temas escolhidos pelos próprios alunos); a preparação da aula de Modelagem; os conteúdos préestabelecidos do currículo escolar (centrado no livro didático), e tantos outros, podem ser considerados como fontes geradoras de tensões que operam para que muitos professores fiquem receosos em adotar essa tendência (OLIVEIRA, 2010; BARBOSA, 2001a), ou ainda, demonstrem resistência a implementação desta ou de outras inovações pedagógicas. Esses receios decorrem, muitas vezes, dos próprios elementos considerados positivos na literatura, mas que causam estranhamento aos professores que se deparam com outras ideias e práticas "estranhas" (KLÜBER et al., 2016b).

No contexto destas preocupações, um projeto de formação continuada de professores em Modelagem Matemática na Educação Matemática ${ }^{5}$ está em andamento nos Municípios de Cascavel, Foz do Iguaçu, Francisco Beltrão e Guarapuava, no Estado do Paraná. O projeto é pautado em um modelo de formação de professores que envolve o diálogo, a pesquisa, a prática reflexiva e outros aspectos que buscam superar modelos de formação vigente marcados apenas pela atualização do professor (GÁRCIA, 1999), na área de Modelagem.

\footnotetext{
${ }^{3}$ Faculdade de Filosofia, Ciências e Letras de Guarapuava.

4 Universidade Estadual do Centro Oeste.

5 Projeto de Projeto de Extensão Formação de Professores em Modelagem Matemática na Educação Matemática aprovado em 28/10/2015 sob o parecer 087/2015-CCET, o qual está vinculado ao Projeto de Pesquisa Formação de Professores em Modelagem Matemática na Educação Matemática: Compreensões e desvelamentos.
} 
Vale ressaltar que a formação, objeto de nosso relato, tem por finalidade a inserção dos professores em um ambiente de discussão e reflexão sobre diferentes assuntos relacionados ao ensino e à aprendizagem da Matemática, à prática pedagógica do professor e o experienciar das atividades de Modelagem, possibilitando, assim, a implementação da Modelagem Matemática nas suas salas de aula (KLÜBER, et. al, 2015).

Deste projeto mais amplo, focaremos especificamente a formação que ocorre na cidade de Francisco Beltrão, Paraná. Antes de passarmos ao relato da experiência, faremos na seção seguinte, a explanação do projeto de extensão: Formação Continuada de Professores de Matemática em Modelagem Matemática na Educação Matemática.

\section{O PROJETO DE FORMAÇÃO CONTINUADA EM MODELAGEM MATEMÁTICA NA EDUCAÇÃO MATEMÁTICA}

O projeto de extensão, ao qual nos referimos ocorre, especificamente, nos municípios ${ }^{6}$ de Cascavel, Foz do Iguaçu, Francisco Beltrão e Guarapuava, no Paraná. O projeto é coordenado pelo Doutor Tiago Emanuel Klüber, docente da Universidade Estadual do Oeste do Paraná, Unioeste, campus de Cascavel, e foi implementado nos municípios citados por meio dos formadores-formandos ${ }^{7}$, mestrandos em Educação (Campus de Cascavel) e do Mestrandos em Ensino (Campus de Foz do Iguaçu) no ano de 2015. Todos são membros do grupo de pesquisa: Formação de Professores de Ciências e Matemática - FOPECIM - da UNIOESTE, na linha de pesquisa "Modelagem Matemática na Educação Matemática e Formação de Professores". É importante destacar que os formadoresformandos são, também, professores da Educação Básica, nas escolas onde o projeto se desenvolve.

Enfatiza-se que este projeto é estruturado de modo a valorizar as trocas intersubjetivas, propondo que a formação se desenvolva no ambiente do professor - a escola - e no período, também, destinado à formação - a hora-atividade ${ }^{8}$. O quadro 1 expõe de maneira breve as quatro etapas do projeto e as estratégias utilizadas para a concretização delas.

Quadro 1: Etapas, estratégias e procedimentos da proposta de formação.

\footnotetext{
${ }^{6}$ A formação iniciou também nos municípios de Assis Chateaubriand e Tupâssi, porém, por motivos estruturais ela não acontece mais.

7 Termo estabelecido, segundo Klüber, et. al. (2015), em analogia àquele de Freire (1996) Educador-Educando. Busca demonstrar a dependência entre os sujeitos envolvidos na formação e o formador.

${ }^{8}$ A viabilidade da proposta da formação de utilizar a hora-atividade ocorre em consonância com a Lei $n^{\circ} 11.738$, de 16 de julho de 2008, a qual regulamenta que, no mínimo, $1 / 3$ da jornada de trabalho dos professores, deve ser utilizada como hora-atividade, período que o professor não está em sala de aula, mas desenvolve atividades referentes a ela. Como exemplo, a preparação das aulas, elaboração de materiais didáticos, elaboração e correção de avaliações, se dedica à pesquisas, estudos e formações.
} 


\begin{tabular}{|c|c|}
\hline Etapas & ESTRATÉGIAS \\
\hline Introdução ao projeto. & $\begin{array}{l}\text { - Análise de constructos pessoais e } \\
\text { teorias implícitas; }\end{array}$ \\
\hline $\begin{array}{l}\text { Inserção no contexto das atividades de } \\
\text { Modelagem Matemática a partir da dinâmica } \\
\text { interna do grupo. }\end{array}$ & $\begin{array}{l}\text { - Práticas em situações simuladas } \\
\text { de classe; }\end{array}$ \\
\hline $\begin{array}{l}\text { Diálogo e prática de Modelagem com vistas à } \\
\text { apropriação de aspectos do estilo de pensamento } \\
\text { próprio da Modelagem Matemática. }\end{array}$ & $\begin{array}{l}\text { - Apoio profissional de colegas } \\
\text { (premissas colaborativas); } \\
\text { - Análise do conhecimento didático } \\
\text { do conteúdo através de árvores } \\
\text { ordenadas; }\end{array}$ \\
\hline $\begin{array}{l}\text { Experiências pedagógicas com a Modelagem } \\
\text { Matemática seguidas de reflexões sistemáticas } \\
\text { sobre a sua própria ação. }\end{array}$ & $\begin{array}{l}\text { - } \quad \text { redação e a análise de casos; } \\
\text { - } \quad \text { Apoio profissional de colegas } \\
\text { (premissas colaborativas); } \\
\text { - } \quad \text { Aprofundar a correlação; } \\
\text { - Investigar a própria prática e } \\
\text { socializar; } \\
\text { - Elaboração de atividades em } \\
\text { grupos; }\end{array}$ \\
\hline
\end{tabular}

Fonte: Os autores - adaptado de Klüber et. al, (2016a, p. 473-474).

Ressalta-se que, como descrito no projeto, as etapas são interdependentes e não lineares, ou seja, não há necessidade de ocorrer a primeira fase, depois a segunda e assim sucessivamente.

$\mathrm{Na}$ seção seguinte faremos o relato de 14 encontros iniciais da formação que está em andamento no município de Francisco Beltrão9. Para salvaguardar as identidades dos participantes, eles serão identificados com a letra "P" de professor, seguido por uma sequência numérica, como no exemplo: P1, P2, P3.

\section{A FORMAÇÃO CONTINUADA NO MUNICÍPIO DE FRANCISCO BELTRÃO}

Para a constituição do grupo de formação, inicialmente, propusemos uma conversa com os professores de Matemática de um dos Colégios do Município Francisco Beltrão, região sudoeste do Paraná, em outubro de 2015. Expusemos brevemente a proposta de formação que,

\footnotetext{
9 A formação iniciou em novembro de 2015 e os encontros aqui relatados se referem ao período de novembro de 2015 a agosto de 2016. Lembramos, ainda, que a formação tem caráter permanente, ou seja, está em andamento e até dezembro de 2019 ocorreram 60 encontros.
} 
inicialmente, aconteceu quinzenalmente na escola, em nosso ${ }^{10}$ local de trabalho e usando parte da hora-atividade.

A proposta, a princípio, deixou os colegas preocupados com o número de participantes, já que normalmente os cursos de formação ocorrem com um número maior de participantes. A explicação de que essa formação foi pensada justamente para que pudéssemos fazer grupos menores e trabalhar em conformidade com a realidade existente na escola, possibilitou, de início, um olhar diferenciado para a formação. A escola que recebeu o projeto, contava com oito professores de Matemática, destes, três, por motivos particulares ou por desempenhar outras funções não se fizeram, num primeiro momento, presentes nos encontros.

\section{PRIMEIROS ENCONTROS DE FORMAÇÃO: AMBIENTAÇÃO E NEGOCIAÇÃO DE CONSTRUCTOS PESSOAIS}

Iniciamos a formação no dia 03 de novembro de 2015, uma terça-feira à tarde. $E$ até dezembro de 2015 foram realizados quatro encontros presenciais que contaram, também, com atividades a distância, como leituras, preenchimento de formulários eletrônicos e questionários necessários ao andamento dos encontros de formação.

O quadro 2 sintetiza a primeira etapa do projeto de formação, que chamamos de ambientação e negociação de constructos pessoais (GARCIA, 1999).

Quadro 2: Síntese dos procedimentos e objetivos da primeira etapa

\begin{tabular}{|c|c|}
\hline Procedimentos & Objetivos \\
\hline $\begin{array}{l}\text { - } \\
\text { - } \\
\text { - } \\
\text { dopresentação dos professores participantes; } \\
\text { matemática, o motivo pelo opção em participar do projeto e } \\
\text { as quais as expectativas deles. } \\
\text { - } \quad \text { Solicitar a descrição sobre o que os formandos- } \\
\text { formadores pensam sobre currículo, planejamento, } \\
\text { abordagem dos conteúdos, cotidiano da escola, condução } \\
\text { de atividades; } \\
\text { - } \quad \text { Compartilhar as "descrições" entre os professores; } \\
\text { - } \quad \text { Realizar leituras de textos correlatos aos temas } \\
\text { levantados pelos professores; }\end{array}$ & $\begin{array}{l}\text { - Proporcionar a dos } \\
\text { ambientação } \\
\text { participantes; } \\
\text { - Proporcionar } \\
\text { momentos de discussão } \\
\text { sobre temas relevantes ao } \\
\text { contexto escolar e a rotina } \\
\text { do professor; } \\
\text { - Reflexão sobre a } \\
\text { própria ação; } \\
\text { - Negociação de } \\
\text { concepção e constructos } \\
\text { pessoais. }\end{array}$ \\
\hline
\end{tabular}

Fonte: os autores - adaptado de Klüber et. al, (2016a, p. 473-474).

\footnotetext{
10 Quando fazemos referência ao nosso local de trabalho é porque a formadora-formanda também atua nessa escola como professora de Matemática.
}

Reflexão e Ação [ISSN 1982-9949]. Santa Cruz do Sul, v. 28, n. 1, p. 273-289, jan./abr. 2020.

https://online.unisc.br/seer/index.php/reflex/index 
No primeiro encontro estavam presentes seis professores (P1, P2, P3, P4, P5, P10): cinco professores da escola, e mais a professora representante da disciplina de Matemática do Núcleo Regional de Educação ${ }^{11}$, que foi convidada a participar dos encontros. Inicialmente cada professor preencheu um questionário que interrogava qual era sua formação, quanto tempo ele atuava em sala de aula, o que tinha a dizer sobre as formações de professores das quais ele já participara e, ainda, quais as expectativas quanto à formação que se iniciava. Após o preenchimento dos questionários cada professor se apresentou, contemplando as respostas do questionário.

Salientamos que esse primeiro momento, responder o questionário de modo individual no início do encontro, foi uma metodologia que se repetiu nos quatro primeiros encontros e teve por objetivo proporcionar ao professor e a nós, o conhecimento de si mesmo, em um momento anterior às discussões coletivas. Segundo a concepção adotada na formação, o professor irá escrever no papel suas primeiras impressões sobre os assuntos abordados nos encontros, de maneira que ele possa refletir e expor suas vivências, seus constructos pessoais. E após esse processo ele expõe e discute suas ideias com os colegas, de forma a refletir sobre o que escreveu, numa perspectiva de olhar para si e interagir com os colegas, produzindo um efeito de autoconhecimento, de reflexão e análise sobre cada assunto tratado nos encontros.

O questionário, desse primeiro encontro, permitiu que conhecêssemos o perfil do professor participante. No nosso grupo, pudemos identificar que todos são professores efetivos ${ }^{12}$ na escola; cinco destes, com 20 ou mais anos de serviço em sala de aula e um deles com 13 anos. A graduação de todos é em Ciências com habilitação em Matemática e, apenas o P3 não participou do Programa de Desenvolvimento Educacional do Estado do Paraná - PDE ${ }^{13}$.

Quanto às formações que os professores participaram anteriormente, os mesmos mencionaram que, em geral, não contemplaram estudos mais específicos de Matemática; que foram insuficientes para dar conta da demanda e das problemáticas atuais e que o tempo destinado às formações é, na maioria das vezes, inadequado para realizar as atividades. Eles sugeriram oficinas que contemplassem as tendências da Educação Matemática.

Com relação às expectativas sobre a formação que se iniciava, as respostas foram: 1) aprender, refletir e discutir sobre a Educação Matemática; 2) pensar na melhoria do ensino e aprendizagem da Matemática; 3) melhorar a prática pedagógica, 4) formar cidadãos mais conscientes

\footnotetext{
11 É importante ressaltar que a professora representante da disciplina de Matemática no Núcleo Regional de Educação de Francisco Beltrão teve papel de participante nos encontros da formação, não interferindo no andamento ou na estrutura da formação, na condição administrativa.

12 Professor efetivo quer dizer professor com concurso público.

13 O PDE é uma política pública de Estado do Paraná, regulamentado pela Lei Complementar n 130, de 14 de julho de 2010. Tem por objetivo propiciar aos professores da rede pública estadual contribuições teórico-metodológicos para que os professores desenvolvam suas ações e redimensionem sua prática. O programa está integrado às atividades da formação continuada e é utilizado para a promoção do professor para o nível III da carreira, conforme previsto no "Plano de carreira do magistério estadual", Lei Complementar $n^{\circ}$ 103, de 15 de março de 2004. Participam do programa professores QPM - Quadro Próprio do Magistério, que estão no nível II, classe 8 a 11 , do plano de carreira. Disponível em< http://www.gestaoescolar.diaadia.pr.gov.br/modules/conteudo/conteudo.php?conteudo=20>, acesso em 20 de Dez. de 2018.
} 
e críticos; 5) lidar com situações em que a Matemática não é bem vista pelos alunos; 6) maior integração entre os colegas da área e 7) troca de materiais didáticos (CARARO; KLÜBER, 2016).

Depois do debate das questões foi apresentado aos participantes o projeto de formação e, segundo eles, a proposta tem como diferencial partir do "chão da escola", além de ser inovadora.

O segundo encontro da formação contou com a participação de quatro professores (P1, P4, P5, P10). Para este encontro utilizamos um formulário online, sem identificação, encaminhado por e-mail para ser respondido durante a semana que antecedeu ao encontro. O formulário, respondido pelos seis participantes da formação, foi base para a elaboração de slides que nortearam as discussões do encontro e questionavam sobre o cotidiano da escola, a rotina do professor, o planejamento escolar, a abordagem dos conteúdos matemáticos em sala de aula, o currículo escolar e sua perspectiva como professor.

No dia do encontro realizamos a leitura do formulário de forma que todos puderam expor suas ideias e confrontá-las com aquilo que eles mesmos tinham escrito. A primeira questão interrogou o professor sobre o cotidiano da escola. As respostas foram que, por muitas vezes, esse cotidiano se torna cansativo, monótono, que cada professor trabalha de forma isolada. Eles indicam que não dispõem de tempo para um planejamento coletivo, por área, ou por série; que a interdisciplinaridade dificilmente ocorre; que tudo é muito burocrático; que cada professor tem seu espaço definido, que seus horários não podem ser ultrapassados; que o tempo para preparo e correção das atividades é insuficiente.

Todavia, uma das respostas suscitou bastante reflexão para nós, enquanto formadores, pois considerou que apesar da tecnologia disponível o cotidiano da escola é o mesmo de anos atrás e que, por mais que se busque inovar, os alunos aprendem mesmo é com a explicação do professor no quadro e no individual.

Outra questão indagou os professores sobre a rotina de trabalho dos formandos-formadores. Eles responderam que preparam suas aulas na escola e em casa; corrigem provas e trabalhos; preenchem livros de registros; cumprem os horários em sala e de hora-atividade; interagem com os colegas da disciplina e de outras áreas e que poucas vezes compartilham experiências pedagógicas com os colegas.

A interrogação da sequência abordava a relevância do planejamento das aulas. Nas respostas, os formandos-formadores disseram que devido aos horários determinados é de suma importância planejar que conteúdo será aplicado, posto que sem planejamento o professor não sabe o que vai trabalhar com o aluno e esse é um motivador para gerar indisciplina na sala de aula. Apenas um professor disse estar disposto a ser flexível em seu planejamento se fosse necessário.

A próxima pergunta do questionário indagava como ocorre a abordagem dos conteúdos Matemáticos em sala de aula. As respostas afirmaram que é necessário levar em consideração o interesse do aluno; que os conteúdos devem ser abordados a partir de uma situação-problema, resgatando os conhecimentos dos alunos; partir da vivência dos alunos e utilizando-se de metodologias que proporcionam situações de investigação, exploração e manipulação.

Ao questionarmos em relação ao que tange a compreensão dos formandos-formadores sobre o currículo escolar, as respostas foram que ele é uma organização da escola, do Estado; um norte para 
os professores, o qual deve ser reorganizado sempre que houver necessidade da escola; que é um conjunto de ações planejadas e aplicadas buscando alcançar um resultado; uma organização de conteúdos por disciplina previamente estruturada nas Diretrizes Curriculares da Educação - DCE.

Quando indagados a respeito de suas perspectivas como professor, as respostas incidiram sobre conseguir que seu aluno veja sentido no que está aprendendo; sobre a escola como um espaço para desenvolver talentos nas mais diversas áreas; de adquirir conhecimento, troca de experiências; de conseguir orientar os alunos na aprendizagem e nos conteúdos científicos apesar do desinteresse de alguns deles.

Como formadores-formandos, percebemos que as questões propiciaram a reflexão sobre muitos pontos referentes à prática pedagógica do professor, o debate foi produtivo, proporcionando a nós o autoconhecimento e a análise de nossas concepções. Foi uma abertura para a reflexão sobre a própria prática e os demais aspectos que compõem a realidade escolar.

Os encaminhamentos do encontro produziram um clima de diálogo entre colegas da área que se mostraram menos inibidos pelas discussões. Propiciando que as ideias fossem expostas, refletidas e debatidas entre todos os participantes.

O encontro foi finalizado com um vídeo organizado pelos formandos-formadores, com excertos da última entrevista de Paulo Freire: uma reflexão sobre o ser professor. Uma motivação para ensinar e aprender na perspectiva da Educação Matemática, a qual tem a intenção, desafiadora, de colaborar para a formação de um cidadão mais autônomo, crítico e atuante no seu contexto social.

O terceiro encontro contou com a participação de cinco professores (P1, P2, P3, P5, P10). No início do encontro eles responderam um questionário que indagava sobre o que entendiam por prática pedagógica e o que orientava essa prática. Questionava, ainda, se o professor utilizava, em suas aulas, alguma das tendências da Educação Matemática e em que situações. Na sequência, como nos encontros anteriores, as questões foram debatidas coletivamente.

Após o debate das questões, trabalhamos com alguns slides que continham excertos de textos relacionados à Educação Matemática. Esses excertos possibilitaram discussões referentes ao que dizem os autores e a contextualização com nossas vivências em sala de aula. É relevante mencionar que, anterior ao encontro foi disponibilizado aos participantes, via e-mail, um texto com recortes sobre Educação Matemática, com a intenção de trazer para o professor um pouco do contexto sobre essa área de pesquisa.

No quarto encontro estavam presentes cinco professores (P1, P2, P3, P4, P10), novamente iniciamos com um questionário que interrogou o que o professor entende por Modelagem Matemática e se ele já tinha desenvolvido alguma experiência utilizando essa tendência. Solicitando que ele a descrevesse. Questionamos, ainda, como ele avaliava a formação até o momento e quais as sugestões para os encontros futuros.

Nesse sentido, do primeiro ao quarto encontro nos detemos à primeira fase sugerida no projeto de extensão, "[...] inserir os professores num ambiente onde ele possa rever, descrever, explorar, compartilhar e negociar os seus constructos pessoais, bem como suas teorias implícitas [...]" (KLÜBER, et.al, 2015, p. 2). 


\section{A INSERÇÃO DA MODELAGEM MATEMÁTICA NA FORMAÇÃO}

O quinto encontro da formação, primeiro encontro de 2016, contou com a presença de seis participantes (P1, P3, P4, P5, P614, P10). Esse encontro desencadeou o que chamamos de segunda fase da formação continuada, que visava a prática com Modelagem Matemática. Primeiramente, desenvolver a prática com Modelagem no grupo de formação e, posteriormente, se fosse do interesse do professor, nas salas de aula, concretizando a terceira fase da formação. Durante essa fase, aspectos da primeira fase foram constantemente retomados.

O quadro 3 expressa os procedimentos e os objetivos daquilo que definimos como segunda e terceira fase da Formação Continuada em Modelagem Matemática.

Quadro 3: Síntese dos procedimentos da segunda e terceira fase da formação

\begin{tabular}{|c|c|}
\hline Procedimentos & Objetivos \\
\hline $\begin{array}{l}\text { - Práticas de Modelagem Matemática } \\
\text { elaboradas pelos formadores-formandos; } \\
\text { - } \quad \text { Elaboração coletiva de atividades de } \\
\text { Modelagem Matemática. }\end{array}$ & $\begin{array}{l}\text { - Propiciar vivências práticas com } \\
\text { atividades de Modelagem Matemática; } \\
\text { - } \quad \text { Discussão e debate sobre a } \\
\text { estrutura de uma atividade de Modelagem } \\
\text { Matemática; } \\
\text { - } \quad \text { Incentivar o professor a desenvolver } \\
\text { seu próprio material pedagógico; } \\
\text { - } \quad \text { Reflexão sobre as possibilidades de } \\
\text { ensino com a Modelagem Matemática. }\end{array}$ \\
\hline
\end{tabular}

Fonte: os autores - adaptado de Klüber et. al, (2016a, p. 473-474).

A proposta para o quinto encontro foi a realização de uma atividade de Modelagem Matemática elaborada pelo grupo de formadores-formandos. Uma atividade semelhante ao primeiro caso, como define Barbosa (2001b), com tema e questão já estabelecidos, bem como, textos de apoio para o levantamento de dados. O tema da atividade foi a "Dengue", visto a repercussão e a presença deste assunto na mídia, assim como a preocupação com a proliferação do mosquito causador, não apenas da Dengue, mas também de Zika e Chikungunya ${ }^{15}$ e teve como interrogação: Considerando o crescimento médio do número de casos de dengue no estado do Paraná e/ou outro município do estado, no mês de fevereiro e o critério estabelecido pelo Ministério da Saúde para que seja declarada epidemia, em quanto tempo as cidades de Curitiba, Londrina, Maringá, Cascavel e Toledo elou estado levaria para ser declarado em epidemia de dengue? A proposta de desenvolver a atividade foi bem aceita pelos participantes que, em grupos, foram lendo e buscando soluções para a questão que

\footnotetext{
14 Professora lotada na escola onde o projeto acontece e que iniciou na formação no quinto encontro.

15 A Zika e a Chikungunya, assim como a dengue são doenças adquiridas por meio da picada do mosquito Aedes aegypti, mas no início de 2016, tiveram grande repercussão devido aos inúmeros casos contabilizados em todo o país.
} 
perguntava sobre a possibilidade de epidemia da doença em algumas cidades paranaenses. Ao final da atividade foram realizadas socializações e eles comentaram sobre as possibilidades de desenvolvêla, tanto com alunos do Ensino Médio, como com alunos dos Anos Finais do Ensino Fundamental.

No sexto encontro estavam presentes seis participantes (P1, P5, P6, P7 16, P817, P10). Nesse encontro realizamos o debate sobre a atividade desenvolvida no encontro anterior. Em relação a essa atividade, os formandos-formadores comentaram que ela pode ser adaptada a diferentes turmas, desde o sexto ano do Ensino Fundamental até o terceiro ano do Ensino Médio. Todos afirmaram que desenvolveriam a atividade em sala de aula. Salientaram a preocupação com o tempo, com as dificuldades de aprendizagem e com a avaliação. Eles, também, consideraram que além dos conteúdos matemáticos a atividade trazia contribuições para o dia a dia do aluno, e que o professor conseguiria relacionar a vivência do aluno com os conteúdos matemáticos, desencadeando uma relação interdisciplinar e aliando a teoria e a prática.

O sétimo encontro contou com sete participantes (P1, P4, P5, P6, P7, P8, P10). A proposta foi desenvolver outra atividade de Modelagem, semelhante ao segundo caso definido por Barbosa (2001b), em que o professor define o tema e o problema e a coleta de informações fica a cargo dos alunos.

A atividade proposta, nesse encontro foi elaborada pelos formadores-formandos de Foz do Iguaçu e de Francisco Beltrão e teve como interrogação: Qual a quantidade de água (em litros) que podemos economizar reaproveitando a água que cai do ar condicionado num período de 100 dias letivos? Iniciamos com algumas leituras que nos proporcionaram compreender, entre outras coisas, como o ar condicionado funciona, porque a água cai do ar condicionado e os tipos de ar condicionado ${ }^{18}$ e como é feito o cálculo para saber a potência ideal do ar condicionado para cada ambiente.

Em seguida, os professores se organizaram para coletar os dados in loco, mediram e fizeram as projeções para a solução do problema. Os participantes ficaram impressionados com a projeção de quanta água poderia ser coletada dos aparelhos de ar condicionado, nos períodos matutino, vespertino e noturno no decorrer de 100 dias. Disseram que é uma atividade interessante não só para os alunos, mas para eles, os professores.

No oitavo encontro, estavam presentes quatro professores (P4, P5, P6, P10) e a proposta foi elaborar coletivamente uma atividade de Modelagem. Os possíveis temas, tratados no final do sétimo encontro e por meio de um grupo no aplicativo do WhatsApp ${ }^{19}$, foram: a diferença de consumo entre as lâmpadas (por que usar lâmpadas de Led), trabalhar com dinheiro, genética e probabilidade.

\footnotetext{
16 Professor que iniciou a formação no sexto encontro, não é lotado na escola onde a formação acontece. Foi convidada pela formadora-formanda em uma reunião dos professores de Matemática do município.

17 Professor que, também, iniciou a formação no sexto encontro. Não é lotado na escola onde a formação ocorre, mas, ficou conhecendo a formação por meio do P7 e pediu para participar.

18 No Colégio em que desenvolvemos a atividade há dois tipos de ar condicionado, o de janela e o Split, essas foram as definições tratadas, o que é o ar condicionado de janela e o que é o ar condicionado Split.

19 Para que a comunicação entre os participantes da Formação Continuada fosse mais dinâmica e informal, foi criado no aplicativo do WhatsApp, aplicativo gratuito para troca de mensagens instantâneas por meio de smartphones, um grupo com todos os participantes do grupo de Francisco Beltrão.
} 
No dia do encontro a formadora-formanda disponibilizou alguns textos impressos sobre os temas sugeridos pelos participantes e eles decidiram por trabalhar o tema: salário mínimo, ou seja, decidiram trabalhar com dinheiro que foi uma das sugestões citadas pelo WhatsApp. Escolheram como interrogação da atividade: Quantas cestas básicas podem ser compradas com um salário mínimo? Diante da questão foram levantados questionamentos que nortearam as pesquisas, como exemplo, quais são os itens da cesta básica? Quais as quantidades de cada item? O que é o salário mínimo? O salário mínimo tem o mesmo valor em todas as regiões do Brasil? Como o salário mínimo é reajustado? Foram selecionados textos para compor a atividade. No âmbito da formação essa atividade se assemelhou ao terceiro caso sugerido por Barbosa (2001b), ou seja, os participantes escolheram o tema, elaboraram a questão e coletaram os dados.

O nono encontro, em que os sete participantes estavam presentes (P1, P4, P5, P6, P7, P8, P10), transcorreu no laboratório de informática da escola e, primeiramente, fizemos a análise da atividade elaborada no encontro anterior. Visualizamos alguns pontos que não estavam claros na atividade, como exemplo, para quantas pessoas foram elaborados os modelos de cestas básicas utilizados na atividade. Encerrada essa atividade, passamos à proposta de em duplas, elaborar uma atividade de Modelagem Matemática. As duplas passaram, então, a discutir os possíveis temas e realizar pesquisas.

No décimo encontro, novamente, todos os participantes estavam presentes (P1, P4, P5, P6, P7, P8, P10). Nesse momento foi dado continuidade à elaboração das atividades de Modelagem, cujos temas de interesse foram a capacidade de armazenamento de fotos no dispositivo móvel, a reciclagem do lixo e os impostos. Nesse encontro recebemos a visita do coordenador do projeto. Fizemos nos minutos finais, uma roda de conversa em que o coordenador agradeceu a disponibilidade de participação de todos e reforçou que a ideia do projeto é propiciar um espaço, na escola e durante a hora-atividade, para que possamos compartilhar nossas experiências, nossos desafios enquanto professores de Matemática e discutir, de forma horizontal, possibilidades e desafios para a implementação da Modelagem Matemática, bem como, incentivar a pesquisa e a divulgação dessa importante tendência, principalmente, nos ambientes da Educação Básica em que estamos inseridos.

$\mathrm{Na}$ sequência, os participantes relataram suas impressões sobre o projeto. O P4 expôs sua opinião mencionando que a troca de experiências que tem sido realizada no decorrer dos encontros é algo positivo, extremamente importante para a formação e que tem aprendido bastante sobre a Modelagem Matemática e suas concepções. O P720 falou que cada vez que vem para a formação consegue levar novidade para sua sala de aula, e que aprende muito entre os colegas da Matemática. O P6 complementou que essa formação favorece o interesse por assuntos sociais que fazem refletir sobre o cotidiano. Disse, ainda, que não se faz mais atividades de Modelagem Matemática em sala de aula porque há a preocupação em vencer conteúdos, se referindo ao currículo escolar. O P1 destacou, ainda, que é professor de Ciências e Matemática e que na atividade desenvolvida sobre $\mathrm{O}$ ar condicionado ( $7^{\circ}$ encontro), pôde visualizar outras possibilidades para trabalhar os conteúdos de Ciências e vice-versa, aliando o olhar das duas disciplinas.

${ }^{20} \mathrm{O}$ P7 tem formação em Física, mas atua na área da Matemática e da Educação Especial. 
O coordenador encerrou o encontro enfatizando que o fato de estudarmos juntos fortalece o grupo, e que se todos estão estudando a mesma coisa, tem-se a possibilidade de compartilhar diversas experiências o que é importante para a manutenção da formação e ampliação dos conhecimentos.

O décimo primeiro encontro deu início às apresentações das atividades elaboradas pelos formandos-formadores, terceira e quarta etapas da formação. Etapas que objetivavam o diálogo e a prática de Modelagem com vistas à apropriação de aspectos do estilo de pensamento próprio da Modelagem Matemática incentivando a realização de experiências pedagógicas com ela e reflexões sobre a própria ação.

Neste encontro, todos os participantes estavam presentes (P1, P4, P5, P6, P7, P8, P10). Os professores P4 e P6, fizeram uma breve explanação de como chegaram ao tema da atividade e em seguida, no coletivo, desenvolvemos a atividade que tem como título: Qual a quantidade de fotos que se pode armazenar em um celular? Durante o encontro surgiram comentários de que a atividade propiciou informações novas e interessantes, não só para o aluno, porém também para nós, professores e, que extrapolamos, segundo nosso entendimento, o nível que poderia ser desenvolvido pelos alunos.

O décimo segundo encontro contou com a presença de todos os participantes (P1, P4, P5, P6, $\mathrm{P} 7, \mathrm{P} 8, \mathrm{P} 10)$ e iniciou com a apresentação da atividade elaborada pelos professores $\mathrm{P} 1$ e $\mathrm{P} 5$, que teve como tema a reciclagem do lixo e como pergunta motivadora: Você sabe quanto dinheiro podemos juntar com a venda de materiais recicláveis? Eles relataram que a escolha do tema foi movida pelo interesse de desenvolver a atividade com suas respectivas turmas, que são do Ensino Fundamental, anos finais.

O décimo terceiro encontro encerrou o primeiro semestre de formação continuada de 2016. Estavam presentes oito participantes (P1, P4, P5, P6, P7, P8, P921, P10). O P7 e o P8 iniciaram a apresentação da atividade elaborada por eles, a qual teve como questão norteadora: Quanto pagamos de impostos? O P7 iniciou fazendo a apresentação da atividade e uma breve explicação sobre o que desencadeou o tema da pesquisa. A atividade proporcionou um repensar sobre quanto pagamos de impostos e como esse valor é repassado para a população em relação à saúde, educação e principais serviços públicos.

\section{FUNDAMENTAÇÃO TEÓRICA E O CONHECIMENTO SOBRE AS CONCEPÇÕES DE MODELAGEM MATEMÁTICA}

O décimo quarto encontro foi, também, o primeiro encontro do segundo semestre de 2016. Nesse primeiro encontro estavam presentes sete participantes (P1, P4, P5, P6, P7, P8, P10).

Foi a partir do décimo quarto encontro que introduzimos na formação leituras, visando fundamentação teórica sobre a Modelagem Matemática. $O$ quadro 4 expõe os procedimentos e os objetivos dessa etapa.

\footnotetext{
${ }^{21}$ Professor que iniciou a formação no décimo terceiro encontro. Iniciou uma substituição temporária de professor na escola onde a formação ocorre. Foi convidado pela formadora-formanda e aceitou participar.
} 
O quadro 4: Síntese dos procedimentos e objetivos da quarta etapa do projeto

\begin{tabular}{|c|c|}
\hline Procedimentos & Objetivos \\
\hline $\begin{array}{l}\text { - } \text { Relatos de Experiência; } \\
\text { - } \quad \text { Textos sobre Modelagem } \\
\text { Matemática } \\
\text { - } \quad \text { Práticas de Modelagem } \\
\text { - } \quad \text { Concepções e perspectivas de } \\
\text { Modelagem Matemática. } \\
\text { - }\end{array}$ & $\begin{array}{l}\text { - Propiciar aos formandos-formadores } \\
\text { o debate sustentado pela teoria; } \\
\text { - } \quad \text { Discutir e compreender algumas } \\
\text { concepções de Modelagem Matemática; } \\
\text { - Incentivar a realização de práticas } \\
\text { nas salas de aula dos professores } \\
\text { participantes. }\end{array}$ \\
\hline
\end{tabular}

Fonte: os autores - adaptado de Klüber et. al, (2016a, p. 473-474).

Iniciamos o encontro com a leitura do texto: Modelagem Matemática e a Sala de Aula (BURAK, 2004). Após a leitura o texto foi discutido coletivamente. Ainda no decorrer da leitura o P7 comentou que a partir da leitura desse texto entendeu a proposta da formação, em que, primeiro fizemos a prática, se referindo a desenvolver as atividades de Modelagem Matemática em ambiente de simulação de sala de aula e só depois, iniciamos a leitura de textos teóricos sobre Modelagem Matemática. E que dessa maneira era possível compreender o que é a Modelagem Matemática e que há diferentes concepções.

Nesse encontro, trabalhamos ainda, com excertos de textos de Barbosa (2001b), de Ferruzzi, Gonçalves, Hruschka e Almeida (2004). O objetivo foi evidenciar as concepções dos autores e relacioná-las com as atividades desenvolvidas na formação.

A reflexão mais detida sobre o relato apresentado é exposta na seção a seguir.

\section{REFLEXÕES SOBRE A EXPERIÊNCIA VIVIDA NA FORMAÇÃO}

Em relação à Modelagem Matemática e suas potencialidades para o ensino e aprendizagem em nossas salas de aula, compreendemos a partir de experiências próprias de formação continuada, que apenas conhecer o que é Modelagem Matemática ou reproduzir atividades já elaboradas dessa tendência não propiciam ao professor o envolvimento necessário para que ele venha a implementar a Modelagem em sala de aula.

Para que ele se sinta seguro para essa implementação, ele precisa vivenciar, na prática, atividades de Modelagem. É importante ainda, que o professor inicie a elaboração de seu próprio material didático, que ele elabore atividades de Modelagem Matemática, mesmo que a partir de atividades modelo, contudo, adaptada com o contexto de seus alunos.

Uma questão que merece discussão é o fato de o professor expressar que as práticas pedagógicas devem partir do contexto do aluno, do que é significativo para ele, da contextualização dos conteúdos. E, no entanto, no dia a dia da sala de aula esse discurso, em geral, não se efetiva. 
Esse modo de agir dos professores vai além dos discursos de preocupação em cumprir o currículo escolar. Pode ser resquícios de uma formação incipiente, muitas vezes tradicional, que prioriza o paradigma do exercício (SKOVSMOSE, 2000) e a sala de aula com carteiras enfileiradas, uma prática pedagógica aprendida com seus professores e reproduzida sem questionamentos, sem reflexão.

É relevante destacarmos que, enquanto formadores-formandos, discordamos de tal prática pedagógica, pautada no paradigma do exercício e de carteiras enfileiradas, por compreender que nem sempre a posição de enfileiramento dos alunos propiciará uma sala de aula silenciosa e um ambiente propício à aprendizagem, e ainda, esse aspecto se contradiz aos relatos de indisciplina realizados por muitos professores que se utilizam de tais métodos, os quais muitas vezes, se queixam, ainda, da falta de aprendizagem dos alunos.

Compreendemos que o relato dos encontros da formação expressa um itinerário formativo importante para a formação de professores em Modelagem Matemática na Educação Matemática. De certo modo, a formação permitiu romper com a rotina dos professores sem gerar ansiedade. $O$ engajamento que deles se revela, corrobora com a proposta de formação que defende a necessidade de um ambiente de confiança, no qual eles possam se expor para, em seguida, rever a sua postura profissional e pedagógica.

Além disso, o ambiente de formação está epistemologicamente alinhado à Modelagem Matemática, ou seja, se nutre de princípios investigativos e temáticos que superam os modelos de formação pautados em exposição e discurso de convencimento. Há um caminhar dos professores que, mesmo que não seja garantia, abre espaço para a apropriação de uma inovação pedagógica (algo diferente do que é usual na escola), que desafia a tradição escolar, quase que exclusivamente pautada na repetição e memorização. Ainda que o discurso pareça repetitivo, ele se apresenta novo porque mostra que os processos de Formação em tendências inovadoras, também precisam ser inovadores (IMBERNÓN, 2010). 


\section{REFERÊNCIAS}

1. BARBOSA, J. C. Modelagem matemática e os professores: a questão da formação. Bolema, Rio Claro: UNESP, n. 15, p. 5-23, 2001a.

2. BARBOSA, J. C. Modelagem na Educação Matemática: Contribuições para o debate teórico. In: REUNIÃO ANUAL DA ANPED, 24, 2001b. Caxambu. Anais... Caxambu: ANPED, 2001.

3. BIEMBENGUT, M. S.; HEIN, N. Modelagem Matemática no Ensino. 4. ed. São Paulo: Contexto, 2005.

4. BURAK, D. Modelagem Matemática e a Sala de Aula. In: EPMEM - ENCONTRO PARANAENSE DA MODELAGEM NA EDUCAÇÃO MATEMÁTICA, 1, 2004, Londrina. Anais... 2004.

5. CARARO, E. F. F; KLÜBER, T. E. Formação continuada de professores de Matemática em Modelagem Matemática na cidade de Francisco Beltrão- Paraná. In: ENCONTRO PARANAENSE DE MODELAGEM NA EDUCAÇÃO MATEMÁTICA - EPMEM, 2016, Londrina. Anais... 2016.

6. CARARO, E. F. F. O sentido da formação continuada em modelagem matemática na Educação Matemática desde os professores participantes. 2017.186f. Dissertação (Mestrado em Educação) UNIOESTE, Cascavel.

7. FERRUZZI, E. C; GONÇALVES, M. B; HRUSCHKA, J; ALMEIDA, L. M. W. Modelagem matemática como estratégia de ensino e aprendizagem nos cursos superiores de tecnologia. In: WORLD CONGRESS ON ENGINEERING AND TECHNOLOGY EDUCATION - WCETE, 2004, São Paulo Brasil. Anais... 2004.

8. GARCÍA, C. M. Formação de professores: para uma mudança Educativa. Coleção Ciências da Educação. Portugal: Porto Editora, 1999.

9. IMBERNÓN, F. Formação Continuada de Professores. Porto Alegre: Artmed, 10. 2010 .

11. KLÜBER, T. E.; BURAK, D. Concepções de modelagem matemática: contribuições teóricas. Educação Matemática Pesquisa, São Paulo: PUC; São Paulo: EDUC - Editora da PUCSP, v. 10, n. 1, p. 17-34, jan. 2008.

12. KLÜBER, T. E. Considerações sobre prática(s) de Modelagem Matemática na Educação Matemática. In: ENCONTRO NACIONAL DE EDUCAÇÃO MATEMÁTICA - ENEM, 10, 2010, Salvador - BA. Anais... 2010. 
13. KLÜBER, T. E; TAMBARUSSI, C. M; CARARO, E. F. F; MUTTI, G. S. L; SILVA, M. V; MARTINS, S. R. Projeto de Extensão: Formação Continuada de Professores em Modelagem Matemática na Educação Matemática. Cascavel: UNIOESTE, 12p, 2015.

14. KLÜBER, T. E; TAMBARUSSI, C. M; CARARO, E. F. F; MUTTI, G. S. L; SILVA, M. V; MARTINS, S. R. Considerações sobre o Projeto de Extensão: Formação de Professores em Modelagem Matemática na Educação Matemática. SEMINÁRIO DE EXTENSÃO DA UNIOESTE - SEU, 17, Francisco Beltrão, 2016a. Anais... Francisco Beltrão. 2016, p. 469-477.

15. KLÜBER, T. E; MUTTI. G. S; TAMBARUSSI, C. M; MARTINS, S. R. Prática Pedagógica em artigos sobre formação de professores em Modelagem: Algumas considerações. In: ENCONTRO NACIONAL DE EDUCAÇÃO MATEMÁTICA - ENEM, 12, São Paulo, 2016b. Anais... São Paulo: SBEM, 2016.

OLIVEIRA, A. M. P. de. Modelagem matemática e as tensões nos discursos dos professores. 2010. 199 f. Tese de Doutorado (Doutorado em Ensino, Filosofia e História das Ciências) - UEFS, Salvador.

17. SKOVSMOSE, O. Cenários de investigação. Bolema: boletim de Educação Matemática, Rio Claro, n. 14, p. 66-91, 2000.

\section{Elhane De Fatima Fritsch Cararo}

Doutoranda em Educação em Ciências e Educação Matemática da Universidade Estadual do Oeste do Paraná - UNIOESTE, Cascavel. Mestre em Educação pela Universidade Estadual do Oeste do Paraná - UNIOESTE, Cascavel, na Linha de Pesquisa: Ensino de Ciências e Matemática. Especialista em Ensino da Matemática (FACEPAL) e em Educação Especial/Deficiência Intelectual (FAMPER). Licenciada em Ciências Habilitação em Matemática (FACEPAL). Membro do Grupo de Pesquisa Formação de Professores de Ciências e Matemática - FOPECIM, na Linha de Pesquisa: Modelagem Matemática na Educação Matemática e Formação de Professores. Professora do quadro próprio do Magistério do Estado do Paraná (SEED). Professora colaboradora na Universidade Estadual do Centro-Oeste (Unicentro).

\section{Tiago Emanuel Klüber}

Possui graduação em Matemática (2004) e especialização em Docência no Ensino Superior (2006) pela Universidade Estadual do Centro-Oeste - UNICENTRO. É mestre em Educação (2007) pela Universidade Estadual de Ponta Grossa - UEPG e doutor em Educação Científica e Tecnológica (2012) pela Universidade Federal de Santa Catarina - UFSC. Pesquisa nas áreas de Educação e 
Ensino, com ênfase em Educação Matemática, atuando principalmente nos seguintes temas: Modelagem Matemática, Formação de Professores, Epistemologia. Compôs o corpo docente permanente do Programa de Pós-Graduação em Educação, PPGE, Campus Cascavel, entre 2013 e 2016, passando a colaborador em 2017-2018. Compôs o corpo docente permanente do PósGraduação em Ensino, PPGEn, Campus Foz do Iguaçu, 2014-2017 e passou à atuar como colaborador em 2018. Membro e vice-coordenador (2012-2015 e 2015-2018) do GT-10 Modelagem Matemática, da Sociedade Brasileira de Educação Matemática, SBEM. Coordenador do Programa de Pós-Graduação em Educação em Ciências e Educação Matemática da Unioeste, nível de mestrado e doutorado (CAPES, conceito 4), campus Cascavel.

\section{Como citar este documento:}

CARARO, Elhane De Fatima Fritsch; KLÜBER, Tiago Emanuel. Formação continuada de professores em modelagem matemática: um relato de experiência. Reflexão e Ação, Santa Cruz do Sul, v. 28, n. 1, jan. 2020. ISSN 1982-9949. Disponível em:

<https://online.unisc.br/seer/index.php/reflex/article/view/12547>. Acesso em: doi:https://doi.org/10.17058/rea.v28i1.12547. 